\title{
Linguagens imagéticas e cartográficas: ferramentas pedagógicas no ensino da Geografia física
}

\author{
Languages and cartographic imagistic: educationaltools on teaching of physical Geography
}

SANTANA ${ }^{1}$, F. S.; SILVA $^{2}$, J. N. G.

fran_17ss@hotmail.com;

\begin{abstract}
Resumo
O artigo visa reforçar a importância do uso das linguagens imagéticas e cartográficas no ensino da Geografia Física, com base em práticas pedagógicas realizadas durante as regências de classe no Colégio Estadual Professora Glorita Portugal, São Cristóvão-SE. As aulas foram prérequisito avaliativo da Disciplina Estágio Supervisionado em Ensino de Geografia II do curso Geografia Licenciatura/UFS. Foram trabalhados os conteúdos relativos a Relevo e Processos Erosivos, cujos principais recursos didáticos empregados para a problematização das temáticas foram mapas temáticos e imagens de diferentes feições topográficas e eventos erosivos. Efetivou-se ainda uma leitura bibliográfica acerca do ensino de Geografia, análise a livros didáticos para preparação das regências e o diagnóstico escolar para conhecer a ambiência da escola. Nas aulas prezou-se pela exaltação do espaço cotidiano dos alunos, Grande Aracaju, com ênfase para São Cristóvão, interligando-os as escalas regional/nacional/global. Utilizamos como propostas avaliativas a produção de maquetes, mapas mentais e a leitura imagética. Os resultados foram positivos, haja vista que foi aguçada a reflexão dos aprendizes no tocante à leitura de imagens e, consequentemente, do espaço geográfico, além de contribuir no processo de alfabetização cartográfica.
\end{abstract}

Palavras-chave: Geografia Física. Práticas de ensino. Linguagens imagéticas e cartográficas. Espaço cotidiano.

\begin{abstract}
This article aims to reinforce the importance of the use of imagery and cartographic language in the teaching of Physical Geography, based on pedagogical practices carried out during class regencies in State College Professor Glorita Portugal, Saint Kitts-SE. Classes were evaluative prerequisite Discipline Supervised Internship in the course Geography II Teaching Geography Degree / UFS. content relating to relief and Erosion were worked, the main teaching resources used to problematize the themes were thematic maps and images from different topographical features and erosive events. It is also effected a literature reading about geography teaching, analysis of textbooks for preparation of regencies and school diagnosis to know the school ambience. In the lecture is prized by the exaltation of everyday space of the students, Grande Aracaju, with emphasis on St. Kitts, linking the regional / national / global scales. We used as evaluation proposals the production of mockups, mind maps and imagery reading. The results were positive, once it was pointed reflection of learners regarding the reading of images and, consequently, the geographical area, and contribute to the cartographic literacy.
\end{abstract}

Keywords: Physical geography. teaching practices. imagery and cartographic languages. daily space.

\section{INTRODUÇÃO}

O Estágio Supervisionado de Ensino é um tirocínio essencial para a formação de professores, uma vez que, proporciona o contato prévio entre futuros docentes e a educação básica. Essa interação possibilita aos estagiários vivenciar a ambiência escolar e identificar os principais entraves que afligem a escola pública e, consequentemente, buscar meios que revertam e/ou amenizem tais problemáticas.

O papel do docente na sala de aula é imprescindível no processo de ensino-aprendizagem, pois o mesmo proporciona a mediação do conhecimento científico com os saberes empíricos dos

\footnotetext{
${ }^{1}$ Franciele dos Santos Santana. Departamento de Geografia, Universidade Federal de Sergipe, São Cristóvão-SE, Brasil

${ }^{2}$ José Natan Gonçalves da Silva. Departamento de Geografia, Universidade Federal de Sergipe, São Cristóvão-SE, Brasil
} 
alunos adquiridos e formulados nas suas relações cotidianas. Verifica-se que a troca de experiências entre o professor de Geografia e os aprendizes é essencial para a construção dos conceitos geográficos.

Reconhecendo a importância do estágio na preparação e formação profissional do docente, o presente artigo apresenta relatos de experiências do Estágio Supervisionado em Ensino de Geografia II, disciplina da grade curricular do curso de Geografia Licenciatura da Universidade Federal de Sergipe (UFS).

As práticas pedagógicas foram realizadas no segundo semestre letivo de 2012, no Colégio Estadual Professora Glorita Portugal, localizado no Bairro Rosa Elze, São Cristóvão-SE, município incluído na Grande Aracaju. A turma contemplada com o estágio foi o $6^{\circ}$ Ano "A" do Ensino Fundamental do turno vespertino. A classe continha 21 alunos com faixas-etárias entre 11 e 15 anos, cujos discentes procediam da comunidade local e adjacências.

O estágio compreendeu cinco semanas, sendo efetivado nas seguintes fases: diagnóstico escolar, observação, regências de classe e aplicação do Projeto de Ensino em Cartografia: Representações Espaciais. Contudo, nesse artigo será dada ênfase a fase das regências de classe que foram realizadas em seis aulas. As práticas a serem expostas dizem respeito a quatro regências, onde foram trabalhados os conteúdos referentes à: Litosfera e as Formas de Relevo; os Agentes Externos Modeladores do Relevo; e os Processos de Erosão, Transporte e Deposição Sedimentar.

Os relatos a serem apresentados retrata, sobretudo, a importância por parte dos professores de Geografia em atrelarem o conteúdo ministrado ao espaço vivido dos alunos, além da importância de incluírem o uso das diferentes linguagens nos procedimentos de ensino. Dentre essas, destacamse a utilização dos recursos cartográficos e imagéticos, ferramentas essenciais para a leitura do espaço geográfico.

\section{METODOLOGIA}

A metodologia empregada consistiu em leitura bibliográfica, referentes a metodologias de ensino-aprendizagem e ao uso de imagens e da cartografia nas aulas de Geografia, como também, a análise de livros didáticos para a elaboração das aulas. É importante ressaltar que foi efetivado o diagnóstico escolar com a finalidade de obtenção de informações juntamente a administração da instituição acerca da comunidade escolar, além de verificar os recursos didáticos a serem disponibilizados para as regências. 
Em sala de aula, após contato prévio com a professora regente, iniciou-se a fase de observação das aulas ministradas pela mesma, visando conhecer os perfis dos aprendizes, bem como, observar os procedimentos metodológicos utilizados pela docente.

Verificou-se a partir das práticas pedagógicas o aguçamento das habilidades cartográficas dos discentes, como também, o despertar de um olhar mais criterioso no processo de análise de imagens, fatores essenciais para uma leitura precisa do espaço geográfico.

\section{RESULTADOS E DISCUSSÃO}

O ensino de Geografia não deve ser empregado a partir de métodos tradicionalistas e mnemônicos, onde o professor seja o transmissor de informações e o discente um mero receptor. Para Passini (2010, p.37) é preciso "virar a página da Geografia descritiva para discutirmos os fatos geográficos numa abordagem analítica e crítica [...] em que o aluno consiga melhorar seus conhecimentos trilhando o caminho do investigador". Assim, o educando se torna o próprio construtor dos conceitos geográficos, a partir da sua relação interativa e dialógica com o docente e demais aprendizes da turma.

Selbach (2010, p.42) compartilha com esse pensamento ao enfatizar que devemos possibilitar que o aluno transforme "informações que ouve em conhecimento, sendo ajudado pelo professor para perceber todo seu significado e toda a sua amplitude". Esse é o principal dever do educador de Geografia, ou seja, exaltar a importância das indagações dos seus discentes e permitir a construção dos conceitos científicos, a partir dos seus saberes pré-existentes apreendidos nas suas relações cotidianas.

Esse procedimento transcende ao aprendiz que o mesmo é dotado do conhecimento geográfico, haja vista, que a Geografia é feita nas inter-relações estabelecidas entre os homens e a natureza. É necessário superar o senso comum das informações e experiências de vida compartilhadas pelos alunos e propiciar a sua transformação em conceitos. Esse processo é mais importante que a mera reprodução dos conceitos chaves contidos nos livros didáticos (CALLAI, 1999).

No processo de correlação do espaço vivido do aluno, com outros em diferentes escalas, faz-se necessário o emprego de recursos cartográficos, uma vez que, esses além de localizar os fenômenos geográficos, proporcionam a aproximação entre lugares. Oliveira (2011) ressalta que os mapas são amplamente encontrados nos livros didáticos, mas, existe uma considerável dificuldade dos alunos no que diz respeito a sua leitura. Isso está atrelado à fragilidade do ensino da cartografia e a insipiente utilização das suas ferramentas nas séries iniciais, que por vezes perduram até o ensino fundamental maior e médio. 
Deve-se enfatizar que o processo de aprendizagem cartográfica é algo contínuo, precisando ser exaltado em todas as aulas de Geografia e não especificamente em uma unidade avaliativa. Os mapas temáticos, cartas e plantas podem ser utilizados como recursos didáticos em todos os conteúdos ministrados.

No tocante aos mapas mentais, Bueno (2011, p.305) afirma que "o conhecimento espacial adquirido pelos homens consiste, sobretudo, em imagens mentais construídas na trajetória de sua vivência a partir de sua percepção". A representação de desenhos ou mapas pelos alunos podem transparecer sensações, experiências de vida e imagens que, por vezes não são exaltados discursivamente e, portanto, são importantes ferramentas a serem utilizadas nas aulas.

Os mapas mentais expõem a percepção dos alunos acerca dos fenômenos geográficos, a partir do seu espaço vivido ou de imagens idealizadas, ocorrendo à atribuição de valores no processo da análise espacial (PONTUSCHKA; PAGANELLI; CACETE, 2009; BUENO, 2011). Assim, Bueno (2011) enaltece que as representações podem expor particularidades concretas, embutidas na vida cotidiana, mas também, realidades figuradas ou ansiadas pelos discentes.

$\mathrm{Na}$ contemporaneidade se propõe uma aprendizagem da cartografia, que aguce o senso crítico-reflexivo do aluno na análise espacial e não simplesmente o ato de decalcar mapas, procedimento tradicional, concomitantemente, ainda protagonizado por muitos professores de Geografia. É essencial orientar o educando a realizar uma leitura cartográfica do seu espaço vivido, possibilitando-o observar que ele e as pessoas as quais convivem são agentes ativos na transformação do espaço e, portanto, atores sociais que são alvos de estudo da Geografia.

Além disso, ao representar a paisagem por meio de desenhos espontâneos ou mapas mentais, conforme Pontuschka, Paganelli e Cacete (2009, p.298) o aluno trabalha "a coordenação e a transposição do tridimensional (realidade) para um plano bidimensional (papel), artifício utilizado pela perspectiva linear". As autoras ainda enfatizam que esse processo contribui para verificar a aptidão gráfico-espacial dos aprendizes, como também, as noções de proporção, escala e distância.

Permitir aos aprendizes que eles construam materiais didáticos e avaliativos, valoriza a sua criatividade e os tornam envolvidos com o trabalho pedagógico. A produção de maquetes, também se inclui nessa discussão por fazer referência à capacidade de criação do aluno. Além disso, a maquete é uma ferramenta de ensino importante por possibilitar a visualização precisa dos fenômenos espaciais, a partir de uma representação tridimensional (SILVA; MUNIZ, 2012).

É ainda fundamental no ensino de Geografia o emprego de uma alfabetização voltada para as imagens, sejam elas transmitidas em outdoors, fotografias, encartes, jornais ou até mesmo de maneira cênica e audiovisual, pois "há necessidade de, geograficamente, pensar o sentido que tais 
representações têm para a formação cultural de professores e alunos" (PONTUSCHKA; PAGANELLI; CACETE, 2009, p.279).

Analisar fotografias de vários períodos temporais possibilita perceber as transformações do espaço, como também, utilizar imagens de paisagens visualizadas cotidianamente pelos discentes e outras de locais distantes, permite ao mesmo apreender as correlações e distinções entre os lugares. Contudo, nessas análises cabe ao docente estimular a criticidade do aluno acerca do que está expresso em cada imagem.

Utilizar-se de práticas lúdicas como a representação de mapas mentais e a construção de maquetes são formas avaliativas participativas, condicionantes para o desenvolvimento da criatividade do aluno, que ao ser orientado pelo professor encontra caminhos motivadores para um ensino-aprendizagem valorativo (RIBEIRO, 2011). A leitura imagética aguça a criticidade do estudante, proporcionando-o ver com olhares mais reflexivos, o que está por trás das imagens e paisagens por ele visualizado.

\section{Metodologias de ensino na Geografia Física: contribuições do Estágio Supervisionado}

Para as abordagens dos conteúdos Litosfera e as Formas de Relevo, foram utilizadas duas regências com duração de 50 minutos cada aula. A princípio foram lançadas algumas perguntas norteadoras aos alunos como: "Alguém sabe o que venha ser relevo?”; "Vocês já perceberam que existem áreas de relevo mais elevadas que outras?"; "Vocês denotam isso no lugar onde moram ou no percurso de casa até a escola?"; "A superficie da Terra é totalmente plana?". Tais indagações instigaram nos alunos o compartilhamento de informações essenciais para a problematização do conteúdo.

Compete aos professores valorizar os conhecimentos prévios dos discentes no processo de formulação dos conceitos geográficos. Conforme Kaercher (1999, p.13) "no ensino fundamental, é necessário que partamos das paisagens visíveis e não de conceitos (isso cabe mais ao ensino médio). Ou seja, os conceitos não devem anteceder aos conteúdos. Esses devem propiciar que os alunos construam os conceitos".

Os aprendizes ao mencionarem a existência de áreas elevadas no bairro, a exemplo, do Morro do Tijuquinha nas proximidades da escola, além de áreas de planícies mais suscetíveis a inundações, contribuíram efetivamente com o processo de ensino-aprendizagem.

Após uma breve contextualização da temática com os alunos, a aula foi prosseguida de forma expositiva e dialogada, sendo utilizado como recursos didáticos o notebook e o datashow, nos quais foi exposto imagens de relevo, de paisagens em âmbito global, nacional, regional e, 
principalmente, local, a exemplo do Morro do Urubu ${ }^{1}$ em Aracaju e Morro do Tijuquinha em São Cristóvão. Além disso, foram utilizados mapas temáticos das formas de relevo do Brasil e de Sergipe, com ênfase no município de São Cristóvão.

Após a explanação do assunto, foi realizada uma atividade lúdica como sugestão avaliativa. Na dinâmica "Colocando a mão na massa" os alunos construíram a partir da sua percepção, uma maquete sobre as formas de revelo, com o uso da massa de modelar ${ }^{2}$.

A princípio foi explicada a proposta da atividade, a turma foi dividida em quatro grupos de cinco alunos e na sequência foram distribuídos os recursos didáticos necessários para a construção da maquete (massa de modelar, isopor, palito, papel e cola branca). Os alunos com suas próprias mãos modelaram as formas de relevo, distinguindo-as de acordo com as diferentes cores das massas de modelar e com as placas de palito (Figuras 01 e 02). É importante frisar que todos os educandos participaram ativamente da dinâmica, valendo ressaltar a preocupação em construir as formas de relevo visualizadas no seu cotidiano, como também, em comparar e distinguir as diferentes feições topográficas.
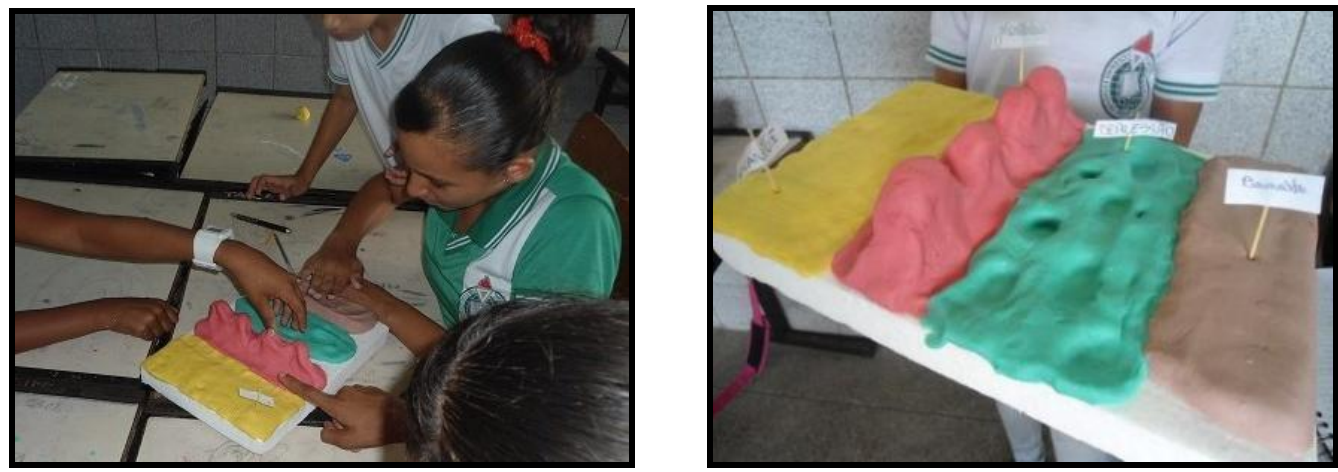

Figuras 01 e 02: Processo de modelação das formas de revelo e maquete construída.

Fonte: Franciele dos Santos Santana ; José Natan Gonçalves da Silva; 2013.

A massa de modelar é um material que pode ser reutilizado para a construção de diversas maquetes, inclusive referentes a outros conteúdos. Nesse sentido, propõe-se a utilização de recursos didáticos práticos, que possam ser reaproveitados em outras práticas de ensino e que não se tornem meros objetos descartados como, por vezes ocorre nas escolas.

No processo de realização da atividade foi despertado o prazer e a curiosidade dos alunos com a aprendizagem, tornando-os agentes ativos na construção do conhecimento, propósito também defendido por Silva e Muniz (2012). A dinâmica proporcionou o envolvimento dos estudantes com

\footnotetext{
${ }^{1}$ Este faz parte de uma Unidade de Conservação de Uso Sustentável, a Área de Proteção Ambiental do Morro do Urubu.

${ }^{2}$ Sugerimos a utilização da massa de modelar caseira para a redução de custos. Para a produção da massa são necessárias 2 xícaras de farinha de trigo, 1/2 xícara de sal de cozinha, 1/2 xícara de água e a quantidade de tinta guache desejada para a coloração da massa. Caso queira torná-la mais consistente adicione aos poucos mais farinha de trigo.
} 
um conteúdo, considerado por vezes não atraente. Foi Exercitado ainda as suas habilidades cartográficas, no que diz as noções de escala, proporção e representação tridimensional do espaço geográfico. A cartografia é antes de tudo uma ferramenta da Geografia e, portanto, deve ser sempre utilizada nas aulas dessa disciplina.

A segunda prática pedagógica foi realizada em duas horas aulas com base nos seguintes conteúdos: Agentes Externos Modeladores do Relevo e os Processos de Erosão, Transporte e Deposição Sedimentar. As perguntas que nortearam a prática de ensino indagavam: "Vocês conhecem as etapas do processo erosivo?”; "O que entendem por erosão a partir da água, do vento, do gelo e dos seres vivos?”; "E os seres humanos influenciam na ocorrência dos eventos erosivos?"; "Já vivenciaram ou conhecem algum problema ocasionado por processos erosivos"; “Conhecem alguma ação dos seres humanos para amenizar a ocorrência desses eventos?”.

A partir de então os alunos expuseram seus conhecimentos, trazendo exemplos de movimentos de massa, ação erosiva do mar sobre a costa litorânea, fenômenos conhecidos através dos meios de comunicação, sobretudo, da televisão e da internet, ou que retratavam experiências vivenciadas pelos mesmos.

Após uma breve problematização do conteúdo a aula prosseguiu de forma expositiva e dialogada com a exposição de imagens, mapas temáticos e esquemas por meio de cartazes ilustrativos. Nas regências executadas, prezou-se pela diversificação dos materiais didáticos, não se prendendo apenas a um recurso. O professor deve ser ousado e trazer sempre algo de novo para suas aulas, que atraia a curiosidade do aluno e desperte o seu interesse pela aprendizagem. Foram utilizados ainda o pincel e o quadro branco, por sua vez, esses não foram empregados para transcrever enormes fragmentos de texto, mas, para produzir desenhos esquemáticos.

Os cartazes continham imagens de processos erosivos em escala regional, nacional e global, como também, ilustrações desses eventos na Grande Aracaju, locais conhecidos pelos aprendizes, como: a suscetibilidade de deslizamento de terra no Morro do Urubu - Aracaju e no Morro do Tijuquinha - São Cristóvão, plantação de gramíneas em uma vertente antropizada no Bairro América - Aracaju, para diminuir os efeitos da erosão pela ação da água, preservação da vegetação de restingas em dunas da Praia de Atalaia - Aracaju, para conter o transporte eólico de sedimentos, dentre outros.

Priorizar o local, o bairro, a cidade, o espaço vivido dos alunos nas aulas de Geografia é uma proposta incentivada por Kaercher (2011). Recorrer a paisagens visualizadas rotineiramente pelos discentes despertou-lhes o olhar geográfico sobre as mesmas, condicionando-os atribuí-las significados sistematizados. 
Como propostas avaliativas, a princípio os alunos elaboraram de modo individual, um mapa mental a partir dos conhecimentos adquiridos na aula e apreendidos em sua experiência de vida, referentes ao processo desordenado de antropização do relevo. Segue abaixo uma das representações gráficas produzidas pelos estudantes (Figura 03).

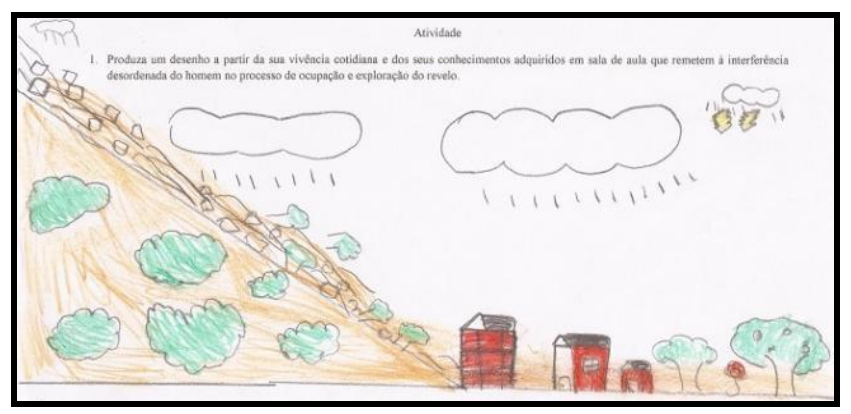

Figura 03: Representação de movimento de massa em área antropizada.

Fonte: José Natan Gonçalves da Silva; Franciele dos Santos Santana, 2013.

No mapa mental, observa-se a percepção do aluno no que diz respeito ao processo de movimentação de massa. A precipitação das nuvens e os raios demonstram que as chuvas influenciam na ocorrência desse processo erosivo. Os sedimentos que deslizam até o sopé da vertente e vão de encontro às residências, evidenciam que essas estão localizadas em áreas inapropriadas para a habitação, ou seja, áreas de risco ambiental.

No processo de discussão com os educandos sobre os mapas mentais, constatou-se que as representações agregavam fatos vivenciados no seu cotidiano, como também, acontecimentos ocorridos em âmbito nacional e local, aprendidos, principalmente, através dos meios de comunicação. Além dos alunos possuírem certo domínio sobre o conteúdo, exercitaram as noções cartográficas de proporção, escala e representação bidimensional do espaço geográfico.

Foi sugerido ainda, que os discentes elaborassem uma pequena história ou texto espontâneo referente à análise de uma imagem que retratava a ocupação humana em áreas suscetíveis a eventos erosivos. Essa atividade foi realizada por cinco grupos, que continham quatro componentes.

Os aprendizes expuseram histórias fictícias atreladas a fatos reais no processo de contextualização da temática. Foram retratas as causas naturais dos eventos erosivos, a interferência antrópica na intensificação dos fenômenos e as consequências catastróficas ocasionadas pela intervenção desordenada do homem sobre essas áreas.

Para Kaercher (2011, p.02) é preciso "através do belo, da imaginação e da interrogação estimular a produção oral e escrita dos alunos na direção de um ensino que atraia o aluno e 
estimule-o a uma leitura mais argumentada e plural do mundo". Instigar os aprendizes a escreverem a partir da leitura do visível é um exercício fundamental no ensino da Geografia Física, sobretudo diante de alunos, não raro, desestimulados com a da alfabetização textual.

\section{CONSIDERAÇÕES FINAIS}

É preciso estimular práticas pedagógicas no ensino da Geografia Física, de modo que valorizem o cotidiano do aluno e os possibilitem compreender a interação do seu espaço vivido com outros locais em escalas regional, nacional e global. Nesse sentido, a cartografia é uma ferramenta imprescindível, uma vez que, proporciona a aproximação entre os lugares e é fundamental para analisar os fenômenos geográficos. É inconveniente tratar a cartografia como um conteúdo a ser ministrado em apenas uma unidade avaliativa, haja vista, que a sua alfabetização é um processo contínuo e, portanto, deve ser exercitada em todas as aulas da disciplina.

Sugere-se a promoção de uma Geografia que valorize a percepção do aluno acerca do espaço geográfico. Práticas de ensino como a construção espontânea de maquetes e mapas mentais, possibilitam transparecer na representação gráfica a concepção real e/ou figurada do educando referente ao conteúdo trabalhado em sala de aula e apreendida no seu espaço vivido. Outro procedimento fundamental no ensino da Geografia é instigar a leitura de imagens. Analisar não apenas o visível, mas também, o que está por trás do que deseja ser transmitido. Além disso, levar para a sala de aula ilustrações de paisagens, rotineiramente visualizadas pelos alunos, desperta a sua atenção e os incentiva a compartilharem conhecimentos, que dizem respeito ao conteúdo trabalhado.

\section{REFERÊNCIAS}

BUENO, Míriam Aparecida. A Geografia escolar e a ideia de lugar no currículo a partir da elaboração de mapas mentais. In: CALLAI, Helena C. (Org.). Educação Geográfica: reflexão e prática. - 1. ed Ijuí/RS: Ed. Unijuí, 2011, p. 295-314.

CALLAI, Helena Copetti. O Ensino de Geografia: recortes espaciais para análise. In: CASTROGIOVANNI, Antonio Carlos et al. Geografia em sala de aula: práticas e reflexões. 4. ed. Porto Alegre: Editora da UFRGS/AGB - Seção Porto Alegre, 1999. p.57-74.

CALLAI, Helena Copetti. Aprendendo a ler o mundo: a geografia nos anos iniciais do ensino fundamental. Cad. Cedes, Campinas, v. 25, n. 66, p.227-247, maio/ago. 2005.

KAERCHER, Nestor André. A geografia é o nosso dia-a-dia. In: CASTROGIOVANNI, Antonio Carlos et al. Geografia em sala de aula: práticas e reflexões. 4. ed. Porto Alegre: Editora da UFRGS/AGB - Seção Porto Alegre, 1999, p.11-21. 
KAERCHER, Nestor André. A geografia escolar não serve para quase nada, mas... Revista Geográfica de América Central (Número Especial EGAL), Costa Rica, p.01-13, 2011.

OLIVEIRA, Adriano Rodrigo. Construir uma didática da geografia e cartografia: entre linguagem cartográfica, cultura, saberes e práticas docentes. In: CALLAI, Helena C. (Org.). Educação Geográfica: reflexão e prática. 1. ed Ijuí/RS: Ed. Unijuí, 2011, p.167-184.

PASSINI, Elza. Prática de ensino de Geografia e estágio supervisionado. São Paulo: Contexto, 2010.

PONTUSCHKA, Níbia Nacib; PAGANELLI, Tomoko Iyda; CACETE, Núria Hanglei. Para ensinar e aprender Geografia. $3^{\text {a }}$ ed. - São Paulo: Cortez, 2009.

RIBEIRO, Emerson. A criatividade em geografia, prática pedagógica e avaliação: lanternas geográficas. Geosaberes, Fortaleza, v.2, n.4, p.61-75, ago./dez. 2011.

SELBACH, Simone. Geografia e didática. Petrópolis, RJ: Vozes, 2010.

SILVA, Vládia da; MUNIZ, Alexsandra Maria Vieira. A geografia escolar e os recursos didáticos: o uso das maquetes no ensino-aprendizagem da geografia. Geosaberes, Fortaleza, v.3, n.5, p.62-68, jan./jun. 2012.

Recebido em: 14/08/2016

Aceito para publicação em: 01/10/2016 